\title{
Hanami ou corpos fogem, vazam, escapam...
}

\author{
Juliana Prochnow dos Anjos* \\ Lívia de Rezende Cardoso**
}

\section{Resumo:}

Trudi e Rudi e Yu e Butoh e quimono e Japão e vassoura e cabelos desajeitados e comida e parque e Fuji e remédios e cerejeiras em flor. O que pode esse encontro? Pensar em corpos femininos e masculinos tem se constituído como um exercício de distribuir funções, objetos e características a um ou a outro tipo de corpo. Nesse artigo, propomos analisar algumas passagens do filme Hanami - Cerejeiras em Flor a fim de problematizar a estabilidade das normas discursivas do "sexo", apoiando-nos na discussão de gênero proposta pela filósofa pós-estruturalista Judith Butler. Aqui, apresentamos personagens como Rudi e Trudi representantes, de início, dos corpos masculino e feminino, respectivamente. Após alguns aspectos marcantes nas vidas dessas personagens, tais como os encontros com Yu e com o Butoh, vemos corpos abjetos serem apresentados na narrativa. Observamos, sobretudo, corpos saírem da fixidez de suas identidades para experimentarem outras maneiras de estar no mundo.

Palavras-chave: Relações de Gênero. Corpo Abjeto. Agenciamento. 


\section{Hanami or Bodies Run Away, Leak, Escape...}

\section{Hanami o Cuerpos Huyen, Transbordan, Escapan...}

\section{Abstract}

Trudi and Rudi and $Y u$ and Butoh and kimono and Japan and broom and clumsy hair and food and park and Fuji and medicine and cherry blossom. What can we expect from this encounter? Thinking about female and male bodies has become an exercise to distribute functions, objects and characteristics to one or to the other type of body. In this article, we aim to analyze some passages of the movie Hanami - Cherry Blossom in order to discuss the stability of the discursive norms of "sex", relying on the discussion of gender proposal by the poststructuralist philosopher Judith Butler. Here, we present characters like Rudi and Trudi representatives, from the beginning, of the male and female bodies, respectively. After observing some remarkable aspects in the lives of these characters, such as the meetings with Yu and Butoh, we see abject bodies being presented in the narrative. We mainly noticed bodies leaving the fixity of their identities to experience other ways of being in the world.

Keywords: Gender Relations. Abject Body. Agency.

\section{Resumen}

Trudi y Rudi y Yu y Butoh y kimono y Japón y la escoba y pelo torpe y la comida y el parque pelo y Fuji y remedios y flores de cerezo. ¿Qué puede hacer ese encuentro? Pensar en los cuerpos femeninos y masculinos se han constituido como un ejercicio para distribuir funciones, objetos y características a uno u otro tipo de cuerpo. En ese trabajo, nos proponemos a analizar algunos pasajes de la película Hanami - Cerezos en Flor con el fin de discutir la estabilidad de las normas discursivas de "sexo", apoyándonos en la discusión de género propuesta por la filósofa postestructuralista Judith Butler. Presentamos en ese trabajo personajes como Rudi y Trudi representantes, inicialmente, de los cuerpos masculino y femenino, respectivamente. Después de algunos aspectos importantes en la vida de esos personajes, como encuentros con Yu y Butoh, vemos que cuerpos abyectos son presentados en la narrativa. Observamos, sobretodo, cuerpos que salen de la fijeza de sus identidades para experimentar otras formas de estar en el mundo.

Palabras Clave: Relaciones de Género. Cuerpo Abyecto. Agencia. 


\section{Introdução}

Trabalho, lar, cuidado, seriedade, dedicação, dança, sonho, maquiagem, exagero, felicidade. Pensar em corpos femininos e masculinos tem se constituído como um exercício de distribuir funções, objetos e características a um ou a outro tipo de corpo. Nesse artigo, propomos analisar algumas passagens do filme Hanami - Cerejeiras em Flor ${ }^{1}$ a fim de problematizar a estabilidade das normas discursivas do "sexo", apoiando-nos na discussão de gênero proposta pela filósofa pós-estruturalista Judith Butler. Aqui, desejamos movimentar o pensamento. Questionar: O que é ser um homem? O que é ser uma mulher? O que podemos chamar de masculino e feminino? O que significa ser homossexual, ser heterossexual? Para se sentir bem em seu corpo, sua pele, seria preciso se identificar com uma dessas categorias? O que torna um corpo viável? Seria possível transpor a fronteira que fixa e materializa o"sexo"?

De acordo com a autora, "as categorias de identidade nunca são meramente descritivas, mas sempre normativas e como tal, exclusivistas" (BUTLER, 1998, p.24). A categoria "sexo" é também, desde o início, normativa uma vez que além de funcionar como uma norma, "é parte de uma prática regulatória que produz os corpos que governa" (BUTLER, 2010b, p. 110). Noções de feminino e masculino serão compreendidas, neste trabalho, como efeitos das normas de gênero, contrariando a existência de corpos naturais, uma vez que "nenhum sujeito é o seu próprio ponto de partida" (BUTLER, 1998, p.18).

Ao realizar análises sobre relações de gênero no referido filme, usamos o conceito de "tecnologia de gênero" explicitado por Teresa de Lauretis (1994). Tal tecnologia seria uma espécie de maquinaria, apoiada em diferentes discursos que circulam culturalmente, que cria os sujeitos homem e mulher específicos de uma sociedade (LAURETIS, 1994). Segundo a autora, é preciso separar gênero da diferença sexual e entendê-lo como produto de variadas tecnologias e discursos. Gênero seria, então, o "conjunto de efeitos produzidos nos corpos" (LAURETIS, 1994, p. 208). Analisá-lo seria apreender técnicas e estratégias por meio das quais o gênero é construído.
Desse modo, articulando o que diz Lauretis (1994) sobre as tecnologias de gênero com as problematizações feitas por Judith Butler sobre sexo e gênero, compreendemos gênero aqui como "os significados culturais assumidos pelo corpo sexuado" (BUTLER, 2010a, p. 24). Afinal, a inscrição de gêneros "é feita, sempre, no contexto de uma determinada cultura e, portanto, com as marcas dessa cultura" (LOURO, 2010, p. 11). A sexualidade, da mesma forma, é "aquilo que qualifica um corpo para a vida no interior do domínio da inteligibilidade cultural" (BUTLER, 2010b, p. 155). Ao concordar com isso, importa entender o"modo como as características sexuais são compreendidas e representadas ou, então, são 'trazidas para a prática social e tornadas parte do processo histórico"' (LOURO, 1997, p. 22). Importa, assim, demarcar essas duas categorias como construções.

Poderíamos aqui considerar gênero, portanto, como a capacidade de o sujeito assumir determinado lugar social, de agir socialmente, de maneira voluntária, de fazer escolhas e decidir sobre si. Em vez disso, daremos destaque à performatividade de "sexo", ou seja, "aquele poder reiterativo do discurso para produzir os fenômenos que ele regula e constrange" (BUTLER, 2010b, p. 111). Entendemos, por sua vez, o "discurso como uma prática" (FOUCAULT, 2006) produtiva. Ao atravessar sujeitos, os discursos convidam-nos a posicionarem-se por meio de "práticas pelas quais os indivíduos foram levados a prestar atenção a eles próprios" (FOUCAULT, 2006, p. 11).

Embasadas em tais definições de gênero e seus modos de funcionamento, passamos a movimentar algumas problematizações trazendo trechos do filme em questão nas quatro partes que se seguem. Em "Ele preferia que nada mudasse. Nunca. Nada. Absolutamente", damos foco à construção do masculino no personagem Rudi em relação ao feminino de Trudi, sua esposa. A morte física e conceitual de Trudi é apresentada em "Ela dedicou quase toda a sua vida a vocês, crianças, e a mim. Em "Estranho. Perturbador. Exagerado. Fora do normal, do previsto, do esperado", narramos como Rudi experimenta outras maneiras de estar no mundo. Por fim, em "O que pode esse encontro?", tecemos algumas considerações em torno do que foi possível problematizar a partir do filme. 
Ele preferia que nada mudasse. Nunca. Nada. Absolutamente.

Homem, alemão, branco, casado pai de dois filhos e uma filha, avô de uma menina e um menino, há vinte anos no mesmo emprego. Pegava o trem sempre no mesmo horário, comia o mesmo lanche: um sanduíche preparado pela esposa e uma maçã. Não se cansava de repetir a sentença uma maçã por dia, sua ida ao médico adia. Esse é Rudi, personagem do filme em análise, cuja rotina tranquila, previsível e estável é apresentada no início da narrativa. Faltando pouco para se aposentar, Rudi não levanta questões sobre suas escolhas, nem gostaria de ter feito nada diferente. Nada. Tenho ido trabalhar toda manhã e voltado para casa toda noite. Éo que eu tenho feito ${ }^{2}$.

Por um lado, a aparente função social desse homem, personagem do filme, era bem desempenhada, à medida que sua vida estava centrada no trabalho e nas suas responsabilidades fora de casa, por outro, havia a correspondência e reafirmação de um suposto "papel feminino" por parte de sua esposa Trudi. Tirar o casaco do marido, calçar-lhe chinelos, oferecer-lhe um jantar, eram as tarefas corriqueiras dessa personagem. Nessa relação entre os gêneros, torna-se clara a "distinção entre os domínios público e privado [na vida das mulheres]" (HARAWAY, 2009, p. 76).

Aos sabores de um conjunto de normas, quer-se uma identidade para um corpo e uma outra para outro corpo. Assim, em um sistema heteronormativo, caberia, apenas, duas identidades de sexo/gênero/desejo: masculino e feminino. Tal hipótese binária encerra "a crença numa relação mimética entre gênero e sexo, no qual o gênero reflete o sexo ou é por ele restrito" (BUTLER, 2010a, p. 24). A heteronormatividade é entendida como um regime da heterossexualidade que "atua para circunscrever e contornar a materialidade do sexo e essa materialidade é formada e sustentada através de - e como - uma materialização de normas regulatórias que são, em parte, aquelas da hegemonia sexual" (BUTLER, 2010b, p. 170). Assim, Rudi corresponde ao que se espera de um corpo masculino: o provedor de sua família, homem centrado e sério. Trudi seria a materialidade de um corpo feminino que, dentro da égide heteronormativa, destina-se à função reprodutiva, de zelo e de cuidado com o lar.

Voltemos à narrativa. Trudi, esposa e mãe dedicada, recebe o diagnóstico de que seu marido sofre de uma grave doença e encontra-se em estado terminal. Sem revelar nada a ninguém, ela sugere que ambos partam em viagem para visitar os seus filhos que moram em outras cidades. Passa as roupas do marido, arruma as malas dos dois e eles seguem para Berlim. No trem, quando o marido reclama fome, Trudi, prontamente, retira da bolsa um sanduíche e uma maçã como de costume.

Em muitas sociedades, para as mulheres, o "seu trabalho era da ordem do doméstico, da reprodução" (PERROT, 2008, p. 109) o que a tornou, embora isso venha mudando atualmente, sempre a rainha do lar, a dona-de-casa, mesmo quando passou a exercer profissões no espaço público (PERROT, 2008): "perfeita secretária: que ela coloque flores e que cuide de seu patrão" (PERROT, 2008, p. 115); nas fábricas como costureiras (RAGO, 2009); nos hospitais como enfermeiras (PERROT, 2008); ou na professora que cuida e educa com amor (PARAÍsO, 2002). Nessa lógica, continua-se a operar com um sentido unitário de mulher, sem considerar a "questão da diferença dentro da diferença" (SCOTT, 1992, p. 87).

Como reflexo desse discurso generificado, as mulheres tiveram uma educação em que não podiam "estragar-se a nenhum talento em prejuízo de seus deveres, já que sua vida, embora menos laboriosa, deve ser mais assídua a suas tarefas corriqueiras" (CORAZZA, 2004, p. 284). Além disso, desde os filósofos das Luzes, mais especificamente com a invenção da Sophia por Rousseau, pensou-se em "formá-las para seus papéis futuros de mulher, de dona-de-casa, de esposa e mãe" (PERROT, 2008, p. 93). O processo de formação da subjetividade Trudi é pautado por mecanismos reiterativos que perpassam as práticas sociais. Afinal, "o mecanismo cultural regulamentado de transformação de masculinos e feminismos biológicos em gêneros distintos e hierarquizados [é] comandado pelas instituições culturais" (BUTLER, 2010a, p. 112).

Essa personagem corresponderia ao que se espera de uma "mulher"? Seu corpo corresponderia às normaliza- 
ções? Materializaria a norma? Da mesma forma, Rudi satisfaria os critérios que o classificariam como "homem"? Seu corpo seria um corpo que pesa? Corpos que pesam, segundo Butler (2010b), são aqueles que "produzem possibilidades morfológicas inteligíveis" através de esquemas regulatórios (BUTLER, 2010b, p.122). São os corpos que importam, o que torna "alguém" viável, uma vez que "qualifica um corpo para a vida no interior do domínio da inteligibilidade cultural" (BUTLER, 2010b, p.111). Consideramos que Trudi e Rudi, nesse ponto da narrativa, são corpos que pesam, que correspondem às normas.

\section{Ela dedicou quase toda a sua vida a vocês, crianças, e a mim.}

A passagem de Trudie Rudi por Berlim, para visitar Klaus, o filho casado e pai de duas crianças, e a filha Karolin, lésbica e casada com Franzi, acaba sendo desastrosa. Os filhos sentem-se muito angustiados em ter que receber os pais, dizem não ter tempo para eles, enfim, contam os dias para que eles voltem para casa. No entanto, a morte inesperada de Trudi muda o rumo da trama. As lembranças trazidas pelo marido sobre os seus interesses nos possibilita observar que Trudi, em um momento da sua vida, não teve um corpo "tão viável" como nos foi até então apresentado. Afinal, como assevera Butler (2010b, p. 164), "fossos e fissuras são abertos, fossos e fissuras que podem ser vistos como as instabilidades constitutivas dessas construções, como aquilo que escapa ou excede a norma, como aquilo que não pode ser totalmente definido".

Diante da morte de Trudi, Rudi comenta com os filhos que ela dedicou quase toda a sua vida a vocês, crianças, $e$ a mim. Distante do pai, Karolin se queixa com os irmãos: não está certo, não é justo, ela não pode simplesmente deixá-lo sozinho conosco (referindo-se ao pai). A mãe-esposa-dona-de-casa-dedicada não poderia ter morrido antes de todos, não poderia deixar para os filhos e para a filha a obrigação que era dela: cuidar do marido.

Apesar de Trudi ter falecido em Berlim, o sepultamento aconteceu na cidade em que ela e Rudi residiam e contou apenas com a presença de Franzi, a namorada da filha do casal. Após a cerimônia, Rudi a convida para tomar um café em sua casa. Na conversa, Franzi comenta como Trudi gostou do espetáculo de dança Butoh que elas assistiram em Berlim. Nesse momento, Rudi afirma que sua esposa também havia dito que nunca conhecera uma moça tão gentil como Franzi. Surpresa, ela reponde: não sou assim, não sei por que ela pensou isso. Ela me contou sobre como sempre quis dançar, tornar-se uma grande bailarina Butoh mais que qualquer coisa em sua vida e quanto gostaria de ir ao Japão para estudar. E como tudo agora ficou diferente. Mas que a vida dela era boa! Aí eu pensei... talvez exista nela uma outra mulher... que ninguém vê... e eu vi essa outra pessoa. Foi isso.

Franzi termina de falar e Rudi se levanta para pegar um livro no formato de flipbook ${ }^{3}$ composto por várias fotos de Trudi dançando Butoh com roupa preta, rosto coberto com maquiagem branca, olhos pintados de preto, batom vermelho e cabelos amassados para cima. Rudi, então, comenta: não gostei, foi tão, tão exagerado. Fiquei envergonhado, não queria que ela continuasse com isso...

A dança em questão, o Butoh, tem um significado especial para o filme e para a presente discussão. Criada no Japão por volta de 1960, foi inicialmente considerada uma forma de expressão marginal, foi chamada de dança das trevas. Seu criador, Kazuo Ohno, afirma que não é possível definir o Butoh, já que expressa muitas ideias diferentes ao mesmo tempo, o que se pode dizer é que essa dança choca e surpreende 4 .

O Butoh recupera a vitalidade e a força do corpo, de um corpo domesticado pelas atividades cotidianas e esmagado pelas regras estabelecidas. O desenho de cada gesto é simbólico. Ele estimula ideias, associações e emoções tramando uma visibilidade: as intensidades, os afetos que atravessam os corpos, a música, os movimentos, são expressos através dos gestos. 0 corpo é o veículo de expressão dos elementos vitais: terra, água, fogo e ar (SOUZA, s/ ano).

Trudi, na sequência de fotos parece não corresponder ao que Rudi esperava dela. Seu corpo parece não se enquadrar em nenhuma categoria já conhecida, não corresponde ao que se espera de um corpo de "mulher". O seu corpo, expresso ali nas imagens do Flipbook, não era 
um corpo legitimado, não era um corpo viável. Seria-o, então, desprezível? Segundo Butler, "corpos abjetos ou deslegitimados deixam de contar como 'corpos' [constituindo-se] um campo de deformação, o qual, ao deixar de ser considerado, como plenamente humano, reforça aquelas normas regulatórias" (2010b, p. 124). Corpos abjetos são entendidos, portanto, como aqueles que "não se conformam às normas de inteligibilidade cultural" (BUTLER, 2010a, p. 39) e são, culturalmente, posições "desvalorizadas e temidas" (REIS, 2011, p. 138).

\section{Estranho. Perturbador. Exagerado. Fora do nor- mal, do previsto, do esperado}

Identidade assombrada? "Normalidade" questionada? Uma sensibilidade Queer? A teoria queer pode nos ajudar nessa discussão à medida que problematiza, contesta "todas as formas bem-comportadas de conhecimento e de identidade" (SILVA, 2002, p.107). Segundo Morris (2007, p. 31), "destruir as práticas de normalização é a chave de activismo queer", uma vez que afirma que "não há nada de 'natural' no sexo" (MORRIS, 2007, p.32) e o que existem são significações, linguagem, discursos que servem para normalizar e estabilizar identidades (SILVA, 2002). Pensar queer "nos obriga a considerar o impensável, o que é proibido pensar" (SILVA, 2002, p.107). Nesse sentido, o próprio pensar tira as nossas "certezas" do lugar, abala nossas "verdades", choca. Seria a oportunidade de parar de ver as coisas como são vistas usualmente, a oportunidade daquilo que está dado possa dar-se de outra maneira (KOHAN, 2007a)? Seria revolução, resistência, criação (KOHAN, 2007b, p.94)?

Partindo do princípio que os sujeitos são "normalizados pelas teias complexas de práticas discursivas" e as subjetividades "produzidas pelas práticas discursivas e não discursivas" (MORRIS, 2007, p.30), passamos a considerar que "o sujeito e o organismo não são absolutamente constantes (...) não estão tampouco estabilizados em si mesmos, nem fixos no lugar" (ROSE, 2001, p.98). Rudi, após a conversa com Franzi, passa a se perguntar se não teria aprisionado Trudi, se não a teria privado daquilo que era mais importante para ela: conhecer o Japão e tornar-se uma bailarina Butoh. Rudi, que até então não levantava dúvidas sobre a felicidade de sua esposa, pa- rece não mais estar seguro disso. Um gato selvagem em uma jaula, essa é a imagem que posteriormente vai utilizar para definir a esposa.

Rudi resolve, então, visitar o filho mais velho que mora no Japão, decidido a "mostrar" o país à Trudi, levando na mala algumas roupas dela. No apartamento do filho, sozinho, sentado em frente à televisão, passeando por alguns canais, encontra uma apresentação de Butoh. Pela primeira vez, consegue assistir à dança. Até então, ver os bailarinos e as bailarinas seminus, maquiados/as fazendo movimentos que ele considerava exagerados, causava-lhe grande desconforto. Após a apresentação na televisão, Trudi veste uma blusa e um colar da esposa e se olha no espelho. No dia seguinte, Rudi sai pelas ruas do Japão vestido com saia, blusa e colar da esposa embaixo do sobretudo e o abre para "mostrar-Ihe" uma cerejeira florida.

Rudi diz ao filho que não sabe onde o corpo de Trudi está... O que ele sabe é sobre os papéis que ele e ela representaram até ali. O que ele sabe é acerca das fronteiras que os atos de cada um possuía. O que ele sabe lhe disse, por certo tempo, muito sobre o que era adequado a um e ao outro. $E$ o que não era também. $O$ que ele sabe é que todo esse policiamento sobre o comportamento de cada um não foi o bastante para serem felizes. Limites e fronteiras dos seres eram o que se sabia. Isso é, justamente, o"lugar de relação, região de encontro, cruzamento e confronto. Separa e, ao mesmo tempo, põe em contato culturas e grupos. Zona de policiamento é também zona de transgressão e subversão" (LOURO, 2008, p. 19). É "o estranho, o incoerente, o que está 'fora' da lei, que nos dá uma maneira de compreender o mundo inquestionado" (BUTLER, 2010a, p. 161).

É época de cerejeiras em flor, o mais bonito símbolo para a temporalidade, fenômeno que dura poucos dias. Praças e parques tornam-se a atração da cidade. Rudi, a caminho de uma praça, detém-se diante de um jovem que segura uma placa com a frase "abraço grátis". Eles se olham, Rudi em tom de brincadeira confirma se é grátis mesmo. O garoto sorri. Ele ainda fica em dúvida e, finalmente, o abraça. Vamos percebendo em pequenos detalhes do filme, a transformação desse personagem sério, metódico e corporalmente rígido em um sujeito que se permite 
sair da sua rotina e vivenciar alguma experiência. A experiência, segundo Larrosa (2002), não abre caminho para a imposição de pensamentos, teorias, verdades, mas para a exposição, pois somente aquele que se expõe é capaz de viver uma experiência.

O sujeito da experiência seria algo como um território de passagem, algo como uma superfície sensível que aquilo que acontece afeta de algum modo, produz alguns afetos, inscreve algumas marcas, deixa alguns vestígios, alguns efeitos (LARROSA, 2002, p.7).

Esse parece ser o caminho do personagem Rudi, uma vez que ele parece sair da fixidez da sua identidade para experimentar outras maneiras de estar no mundo. No parque, Rudi observa de longe Yu, uma dançarina de Butoh, aproxima-se lentamente dela e acompanha seus movimentos atentamente. Rudi retorna no dia seguinte e $\mathrm{Yu}$ explica a ele: Butoh é a dança da sombra. Eu não danço, a sombra dança. Preste atenção, sua sombra dança. Não sei quem é a sombra 'olá, olá, quem é você?' Não responde. Todo mundo pode dançar Butoh. Todos podem, todo mundo tem sombra. Jovem e velho. Mulher e homem. E cada ser vivo. E cada ser morto. Ao mesmo tempo.

A sombra é uma figura interessante nessa narrativa. A sombra não tem identidade. Ela não é homem, não é muIher, não é criança. Ela não é sequer uma, mas uma multidão: você encontra a multidão de sombras dentro de você. Nós nem sabemos quem ela é e, talvez justamente por isso, seja ela quem dance, seja ela capaz de movimentarse! Yu ajuda Rudi a fazer alguns movimentos e enquanto dançam conta a ele que as sombras se vão e que seria preciso agarrá-las, senti-las.

O parque torna-se cenário para novos encontros entre Rudi e Yu. A relação entre eles vai se estreitando a cada dia. Rudi faz para a amiga uma receita que a esposa costumava preparar para ele: "enroladinho de repolho" ou "charuto". Como conversavam em inglês, língua estrangeira para ambos, às vezes não conseguiam comunicar o que queriam. $Y u$ come um dos rolinhos, sobrando dois no prato. Ela aproxima um do outro e diz: agora felizes juntos, inseparáveis. Sem conseguir explicar para $Y u$ como se enrola o recheio nas folhas de repolho, Rudi co- meça a gesticular. Yu, em silêncio, deita-se no chão sobre uma lona azul e começa a se enrolar. Rudi fez o mesmo na outra extremidade e eles rolaram envolvidos na lona até se encontrarem no centro: agora, dois rolos de repolho.

Rudi aparece em outra cena arrumando o apartamento do filho. Varre o chão mecanicamente até se dar conta do movimento que está fazendo. Continua então a varrer, agora, lentamente. Tira a vassoura do chão, gira segurando-a no ar, movimenta-a de um lado para o outro, acompanha-a com os olhos. Seriam tímidos passos de dança? Rudi não se sente bem e cai. Com esforço, abre a sua caixa de remédios, toma um comprimido, aparentando saber que não terá muito tempo de vida. Ainda no chão, observa uma toalha de mesa com a imagem do Monte Fuji. Contemplá-lo era o sonho não realizado de Trudi.

Rudi convida Yu para viajar com ele até o Monte Fuji. Hospedados em um hotel, esperam poder ver o monte, poucas vezes visível por causa da névoa. Em meio à madrugada, Rudi se levanta e avista o monte através da janela do seu quarto. Em silêncio, veste o quimono da sua esposa, maquia o rosto de branco, pinta os olhos de preto, usa batom vermelho, dança o Butoh "com Trudi" e se despede da vida.

Naquele momento, Rudi e Trudi eram um só corpo. Não havia preocupações quanto a quem era um ou quem era o outro. O que era de um e o que era do outro. Esse ponto da narrativa nos dá mostra de que não se pode entender que "a construção de 'homens' aplique-se exclusivamente a corpos masculinos, ou que o termo 'mulheres' interprete somente corpos femininos" (BUTLER, 2010a, p. 24). Isto porque, "o poder não'pode' nada contra o sexo e os prazeres, salvo dizer-lhes não; se produz alguma coisa, são ausências e falhas; elide elementos, introduz descontinuidades, separa o que está junto, marca fronteiras" (FOUCAULT, 2010, p. 93). Desse modo, produz-se corpos abjetos. Ali, naquele instante, ele tornou-se um sujeito queer, um corpo da diferença, uma subjetividade "que não quer ser assimilada ou tolerada, e, portanto, sua forma de ação é muito mais transgressiva e perturbadora" (LOURO, 2008, p. 39).

Após o sepultamento do pai, Karolin, e os dois irmãos conversam Agora ficamos órfãos em menos de seis 
meses. Isso tudo parece um sonho. Ainda não acredito que estou aqui. O que nos contou é tão extraordinário. Não parece com papai. Ele não podia aceitar a morte da mamãe. Em um hotel, com uma garota de dezoito anos. E com roupas de mulher. As roupas da mamãe. Franzi levanta a possibilidade de que, apesar de tudo, quem sabe ele estivesse feliz. Os filhos não concordam, acham que isso não seria possível.

A interpretação dos filhos era clara. O pai não aceitou a morte da mãe e por isso fez o que fez: se relacionou com uma garota de dezoito anos, se vestiu de mulher, vestiu as roupas da falecida esposa. Enfim, apresentou um comportamento estranho, inesperado, anormal. Interpretação dos filhos, busca de um significado para tudo o que ocorreu, "significância e interpretose são as duas doenças da terra" (DELEUZE, PARNET, 1998, P.60)! Optaram pela visão mais simples, mais próxima da norma vigente. Optaram por enquadrá-lo na heteronormatividade.

Ao invés disso, Rudi e Trudi fazem-nos pensar que, antes de se instituir uma "guerra de gêneros" entre ele e ela, seria mais produtivo pensar em uma "guerra aos gêneros" (ROLNIK, 2006). Uma forma de desfazer as normas que "teria o efeito de fazer proliferarem as configurações de gênero, desestabilizar as identidades substantivas e despojar as narrativas naturalizantes da heterossexualidade" (BUTLER, 2010a, p. 211). As versões abjetas de Rudi e Trudi não teriam nos desestabilizado e ensinado mais?

\section{O que pode um encontro?}

Deitar no chão do parque, vestir as roupas da esposa, se maquiar como se pode conferir nas imagens a seguir... Viver coisas que até pouco tempo atrás se encontravam no plano do impensável... Uma bailarina, uma dança, um país, um quimono, uma paisagem... talvez isso não queira dizer nada e a única questão seja "como isso funciona, com intensidades, fluxos, processos, objetos parciais" (DELEUZE, 1992, p.34). Quem sabe pensar em termos de agenciamentos ${ }^{5}$ seria interessante para essa reflexão?
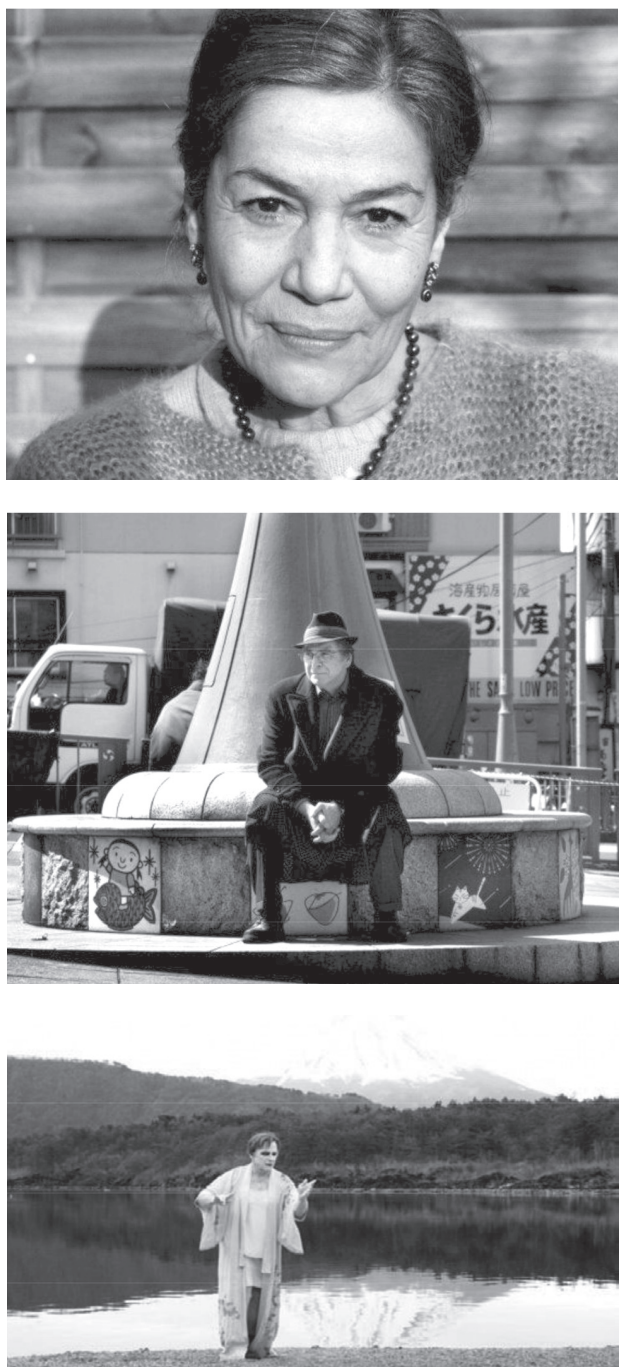

FONTE: Imagens retiradas do filme Hanami - Cerejeiras em Flor.

Essa opção consiste primeiramente em não partir de um sujeito pré-determinado e pela opção de não se buscar observar sujeitos e objetos, a ação desses sobre aqueles, uma vez que se pretende trabalhar em outro plano, no qual o importante seria possibilitar que "o imperceptível seja percebido" (DELEUZE; GUATTARI, 1997a, p.76). Em vez de interpretar: experimentar "todo um mundo de micropercepções que nos leva ao imperceptível" (DELEUZE; PARNET, 1998, p. 61). Nivelar todas as dimensões em um mesmo plano, sem infraestrutura e superestrutura, isso é agenciamento ${ }^{6}$ (DELEUZE; GUATTARI, 1995, p.32)! Mistura de corpos: atrações, repulsões, simpatias, antipatias, alterações, alianças, penetra- 
ções e expansões, ou seja, tudo aquilo que afeta os corpos de todos os tipos (DELEUZE; GUATTARI, 1995, p.31).

Isso porque, nesse plano, "um homem e uma mulher são fluxos, todos os devires que há no fazer amor, todos os sexos, os $n$ sexos em um único ou em dois (...)"aquilo que "não quer dizer nada a não ser o que ele se torna, e me faz me tornar com ele" (DELEUZE; PARNET, 1998, p.61). Proliferar sentidos, aumentar as conexões e assim "liberar a sexualidade não somente em relação à reprodução, mas também em relação à genitalidade" (DELEUZE; GUATTARI, 1996, p.29) através da subtração da unidade principal de um pensamento único, de uma forma única de se ver as coisas. É preciso começar com $n-1$, subtrair o único do múltiplo, a imagem da árvore que sempre cresce e se ramifica a partir de um eixo, de uma ideia principal (DELEUZE; GUATTARI, 1996). O único, a unidade principal, nesse caso, seriam as categorias, as identificações, os lugares pré-determinados para os corpos, os dualismos, tudo aquilo que separa e define o"normal" e o "anormal". Assim, ao invés de acrescentar um elemento para fazer o múltiplo, devemos retirar a ideia única que na imagem de árvore ou raiz afirma a lei do Uno (DELEUZE; GUATTARI, 1996, p.13) e pensar a partir de um sistema de rizoma (idem, p.14-15). Isso porque "toda vez que uma multiplicidade se encontra presa numa estrutura, seu crescimento é compensado por uma redução das leis de combinação" (DELEUZE; GUATTARI, 1996, p.14).

Eu nunca encontrei meu lugar e eu provavelmente nunca encontrarei. Muitas pessoas pretendem que se deveria ter um lugar associado ao seu gênero. Seria necessário se sentir bem em seu corpo, em sua pele. É uma maneira de ver as coisas, mas eu não creio nisso. É que eu sempre estive ligeiramente deslocada em relação às posições dadas. Eu me encaixo mal nas categorias pré-estabelecidas... ${ }^{7}$.

Rizoma que cresce pelo meio e transborda, pois "não é feito de unidades, mas de dimensões, ou antes, de direções movediças (DELEUZE; GUATTARI, 1996, p.32). Porque se nos apegamos somente àquilo que podemos prever e garantir, se buscamos um começo, um fundamento, temos uma falsa sensação de movimento, pois "um rizoma não começa nem conclui, ele se encontra sempre no meio, inter-ser, intermezzo (...) (DELEUZE; GUATTARI, 1996, p.37).
"A árvore impõe o verbo 'ser' mas o rizoma tem como tecido a conjunção e...e...e..." (idem, 1996, p.37). “Corpos que não se definem por seu gênero ou sua espécie, por seus órgãos ou suas funções, mas por aquilo que podem, pelos afetos dos quais são capazes, tanto na paixão, quanto na ação" (DELEUZE; PARNET, 1998, p.74)! Para Deleuze, uma sociedade não para nunca de escapar, de vazar e é justamente esse vazamento que representa um problema para o poder e precisa ser estancado e não o inverso, tentar resistir frente aos aprisionamentos (TADEU, 2004).

Trudi e Rudi e Yu e Butoh e quimono e maquiagem e Japão e vassoura e cabelos desajeitados e comida e parque $e$ Fuji e remédios e multidão de sombras e cerejeiras em flor... O que pode esse encontro?

\section{Notas}

1 Este filme é uma coprodução Alemanha/França de 2008, dirigido e escrito por Doris Dörrie, lançado no Brasil no final de 2009. Informações disponível em <http://www.adorocinema. com/filmes/hanami-cerejeiras-em-flor/ficha-tecnica-e-premios>. Acesso em 21 de junho de 2014.

2 Em itálico serão grafados os trechos retirados do filme Hanami - Cerejeiras em flor, bem como os nomes de seus personagens.

3 Flipbook é um livro composto por imagens em sequência que ao passar as páginas rapidamente provoca uma ilusão de movimento.

4 Cf. <http://www.butoh.com.br/taxon/dancabutoh.html>. Acesso em 21 de junho de 2014.

5 "Agenciamento" é um conceito criado pelo filósofo Gilles Deleuze e desenvolvido posteriormente em parceria com Félix Guattari em contraponto às teorias estruturalistas que se interessam por sistemas relativamente homogêneos e estáveis (KRTOLICA, 2009).

6 É importante destacar que agenciamentos podem também impor o disciplinamento dos corpos, um agenciamento despótico resultaria em significâncias, um agenciamento autoritário, em subjetivações e, finalmente, a mistura dos dois resultaria em agenciamentos de poder (DELEUZE; GUATTARI, 1997b).

7 Documentário Judith Butler: philosophe en tout genre, de Paule Zajdermann, França, 2006. Disponível em <http://www. youtube.com/watch? $v=k S S f J g v H 9 r 8 \&$ feature $=$ related $>$. Acesso em 14 de maio de 2011. 


\section{Referências Bibliográficas}

BUTLER, Judith. Fundamentos contingentes: o feminismo e a questão do "pós-moderno". Cadernos Pagu trajetórias do gênero, masculinidades, Campinas, v. 11, p. 11-43, 1998.

BUTLER, Judith. Problemas de gênero: feminismo e subversão da identidade. $3^{a}$ ed. Rio de Janeiro: Civilização Brasileira, 2010a.

BUTLER, Judith. Corpos que pesam: sobre os limites discursivos do "sexo". In: LOURO, Guacira. L. O corpo educado: pedagogias da sexualidade. Belo Horizonte: Autêntica, 2010b p. 151-172.

CORAZZA, Sandra. História da Infância sem fim. $2^{\text {a }}$ ed. ljuí: Ed. Unijuí, 2004.

DELEUZE, Gilles. Conversações. Rio de Janeiro: Ed.34, 1992.

DELEUZE, Gilles. GUATTARI, Felix. Mil Platôs: capitalismo e esquizofrenia. Rio de Janeiro: Ed. 34, 1996, v.1.

DELEUZE, Gilles. GUATTARI, Felix. Mil Platôs: capitalismo e esquizofrenia. Rio de Janeiro: Ed. 34, 1995, v.2.

DELEUZE, Gilles. GUATTARI, Felix. Mil Platôs: capitalismo e esquizofrenia. Rio de Janeiro: Ed. 34, 1997a, v.4.

DELEUZE, Gilles. GUATTARI, Felix. Mil Platôs: capitalismo e esquizofrenia. Rio de Janeiro: Editora 34, 1997b, v. 3.

DELEUZE, Gilles. PARNET, Claire. Diálogos. São Paulo: Escuta, 1998.

FOUCAULT, Michael. História da Sexualidade I. São Paulo: Graal, 2010.

FOUCAULT, Michael. História da Sexualidade II. São Paulo: Graal, 2006.

HARAWAY, Donna J. Manifesto ciborgue: Ciência, tecnologia e feminismo-socialista do final do século XX. In: HARAWAY, D.; KUNZRU, H.; TADEU, T. (Org.). Antropologia do ciborgue: as vertigens do pós-humano. $2^{\mathrm{a}}$ ed. Belo Horizonte: Autêntica, 2009 pp. 33-117.

KOHAN, Walter Omar. Filosofia e educação. Entrevista concedida em áudio ao programa Logofonia. Rádio UFMG Educativa. Exibido em 20 de Novembro de 2007 (2007a).

KOHAN, Walter Omar. Infância, estrangeiridade e ignorância Ensaios de filosofia e educação. Belo Horizonte: Autêntica, 2007b.

KRTOLICA, Igor. Diagramme et agencement chez Gilles Delleuze - L'élaboration Du concept de diagramme au contact de Foucault. In: Filozofiza I Drustvo, 2009. Disponível em: <http://www.doiserbia.nb.rs/img/doi/0353-5738/2009/0353-57380903097K.pdf> Acesso em: 6 maio 2011.

LARROSA, Jorge. Notas sobre a experiência e o saber de experiência. Revista Brasileira de Educação, n19, Jan/Abrde 2002.
LAURETIS, Teresa. A tecnologia de gênero. In: HOLLANDA, Heloísa Buarque de (Org.). Tendências e impasses: o feminismo como crítica da cultura. Rio de Janeiro: Rocco; 1994. p. 208.

LOURO, Guacira. Pedagogias da Sexualidade. In: LOURO, G. (Org.). 0 corpo educado: pedagogias da sexualidade. $3^{a}$ ed. Belo Horizonte: Autêntica Editora, 2010.

LOURO, Guacira. Um corpo estranho: ensaios sobre sexualidade e teoria queer. Belo Horizonte: Autêntica: 2008.

LOURO, Guacira. Gênero, Sexualidade e Educação: uma perspectiva pós-estruturalista. Petrópolis, RJ: Vozes, 1997.

MORRIS, Marla. O pé esquerdo de Dante atira a teoria queer para a engrenagem. In: TALBURT, Susan; STEINBERG, Shirley R. (org). Pensar queer: sexualidade, cultura e educação. Mangualde, Portugal: Edições pedago, 2007.

PARAÍSO, Marlucy. Currículo e Mídia Educativa: Práticas de produção e tecnologias de subjetivação no discurso da mídia educativa sobre a educação escolar. Tese (Doutorado em Educação) Programa de Pós-Graduação em Educação. Rio de Janeiro: UFRJ, 2002.

PERROT, Michele. Minha história das mulheres. São Paulo: Contexto, 2008.

RAGO, Margaret. Trabalho feminino e sexualidade. In: DEL PRIO$\mathrm{RE}, \mathrm{M}$. (Org.). História das mulheres no Brasil. 9a ed. $2^{\mathrm{a}}$ reimp. São Paulo: Contexto, 2009 pp. 578-605.

REIS, Cristina. Currículo escolar e Gênero: a constituição generificada de corpos e posições de sujeito. Dissertação de Mestrado (em Educação). Belo Horizonte: UFMG, 2011.

ROLNIK, S. Guerra dos gêneros \& guerra aos gêneros. Estudos Feministas. V.4, N.1. Florianópolis: 2006 pp. 01-06.

ROSE, Nikolas. Inventando nossos eus. In: SILVA, Tomaz Tadeu da (Org.). Nunca fomos humanos: nos rastros do sujeito. Belo Horizonte: Autêntica, 2001, p. 137-204.

SCOTT, J. História das mulheres. In: BURKE, Peter (org.). A escrita da história. Novas perspectivas. São Paulo: Ed. UNESP, 1992.

SILVA, Tomaz Tadeu da. Documentos de identidade: uma introdução às teorias do currículo. 2. ed. Belo Horizonte: Autêntica, 2002.

SOUZA, João Roberto de. A dança Butoh. Disponível em: http://www.butoh.com.br/taxon/dancabutoh.html. Acesso em 18 de junho de 2014.

TADEU, Tomaz. Um plano de imanência para o currículo. In:TADEU, Tomaz; CORAZZA, Sandra; ZORDAN, Paola. Linhas de escritas. Belo Horizonte: Autêntica, 2004.

Recebido em: 10/03/2014

Aceito em: 05/04/2014

Publicado em: 30/04/2014 